\title{
Vulnerabilidade à erosão do solo da Região do Alto Rio Pardo, Pardinho, SP1
}

\author{
Fernanda L. Ribeiro ${ }^{2} \&$ Sérgio Campos ${ }^{2}$
}

\begin{abstract}
RESUMO
Com este trabalho se visou à elaboração de um banco de dados com informações cadastrais e de um mapa temático de vulnerabilidade natural à erosão para futuros zoneamento ecológicos da bacia do Alto Rio Pardo, Pardinho, SP, através do Sistema de Informações Geográficas SPRING, utilizando-se da imagem digital do sensor Landsat 7 ETM $^{+}$, e como fonte de dados: mapa de solos, cartas topográficas, geológicas e geomorfológicas e dados de precipitação. O mapa de vulnerabilidade à erosão foi elaborado a partir de regiões espectralmente homogêneas, sendo os pesos médios para cada tema associado a um valor de vulnerabilidade, gerando uma grade resultante da média zonal que, fatiada em termos de vulnerabilidade, resultou no mapa de vulnerabilidade à erosão. Os resultados permitiram concluir que a imagem digital gerou informações valiosas para o mapeamento do uso do solo e formação do banco de dados; o SIG-SPRING foi eficiente na identificação das classes de solo e de vulnerabilidade à erosão; que $95 \%$ da bacia apresentam grau de vulnerabilidade mediana e moderadamente estável, pela presença de solos de média jovialidade, em relevo suave ondulado e coberto por pastagem $(49,27 \%)$ e cultura anual $(29,88 \%)$.
\end{abstract}

Palavras-chave: uso do solo, SIG-SPRING, sensoriamento remoto

\section{Vulnerability to soil erosion of the upper Pardo River, Pardinho, SP}

\begin{abstract}
This study aimed at the elaboration of a database with information and a map of erosion vulnerability for ecological zoning for the upper Pardo River, Botucatu, SP, by using the Geographical Information System - SPRING. The map of erosion vulnerability was made from spectrally homogeneous regions, producing a grid of zone averages, which was then subdivided, resulting in a vulnerability map to erosion. The results allowed us to conclude that digital imaging produced valuable information for mapping of soil use and database formation. The GIS - SPRING was efficient at identifying soil and vulnerability erosion classes and $95 \%$ of the basin presents a moderately stable vulnerability degree, through the presence of medium young soils in gently waring reliefs and covered by $49.27 \%$ of pasture and $29.88 \%$ crops.
\end{abstract}

Keys word: soil use, GIS - SPRING, remote sensing

${ }^{1}$ Parte da Tese de Doutorado do primeiro autor apresentado à FCA/UNESP/Botucatu (SP)

2 FCA/UNESP, CP 237, CEP 18603-970, Botucatu, SP. Fone: (14) 3811-7165. E-mail: seca@fca.unesp.br 


\section{INTRODUÇÃO}

A demanda cada vez mais crescente dos recursos naturais e sua rápida diminuição em escala local, regional, nacional e global, impõem a necessidade de um inventário e planejamento racional desses recursos para a sua manutenção, haja vista que o uso da terra sem um planejamento adequado provoca o empobrecimento dos solos quanto à fertilidade natural, aumenta a acidez, provocando baixa produtividade das culturas trazendo, como conseqüência, os baixos níveis socioeconômico e tecnológico da população rural.

As medidas adotadas para o planejamento do uso do solo foram, até recentemente, tomadas com base em informações fragmentadas de efeitos do uso da terra no ambiente, com virtude de não haver registros seguros sobre as condições adequadas de uso da terra, não se podendo avaliar, portanto, as alterações provocadas pela ação do homem.

Com a crescente demanda dos recursos naturais, o levantamento periódico do uso da terra em uma região tornou a compreensão dos padrões de organização do espaço de interesse fundamental, uma vez que em dado período, quase nunca é permanente, uma vez que o solo está sempre sendo agredido pela ação antrópica.

A constante agressão antrópica, além de, ser comumente desordenada e sem qualquer planejamento de preservação ambiental, provoca um custo financeiro muito elevado nos levantamentos dos recursos naturais por métodos tradicionais; como exemplo, o aerolevantamento, uma vez que este procedimento deve ser realizado a cada ano para se manter atualizadas as informações de ocupação do solo.

Atualmente, para se obter informações sobre a ocupação do solo, o problema dos altos custos pode ser contornado através da utilização de dados coletados por sensores remotos postos a bordo de satélites orbitais, como exemplo, o sensor “Tematic Mapper” (TM) do satélite Landsat, o sensor HRV (high resolution visible) a bordo do satélite SPOT, entre outros.

Para agilizar o processamento desses dados e integrá-los a outras informações, cartográficas, cadastrais etc., é possível utilizar um Sistema de Informações Geográficas (SIG) que permita, ainda, criar um banco de dados gerado ao longo do tempo, possibilitando o acompanhamento e a análise temporal da área de estudo, a qual é de importância regional, uma vez que abrange a nascente do Rio Pardo e a represa de captação da Sabesp, para abastecimento dos Municípios de Botucatu e Pardinho; trata-se de uma área que apresenta problemas concernentes à poluição das águas, degradação dos rios e assoreamento de rios. O uso intensivo do solo sem a conservação adequada, inclusive com plantio de culturas muito próximo às margens, vem provocando esses impasses nos recursos naturais, além de poluição do meio ambiente por resíduos industriais e orgânicos.

Visou-se, neste trabalho, à elaboração do mapa temático de vulnerabilidade natural a erosão que servirá para futuro zoneamento ecológico da área do Alto Rio Pardo, Botucatu, SP; à criação de um banco de dados com informações cadastrais sobre tipo de solo e geologia e à caracterização de cada região quanto a erosão, utilizando-se o SIG - SPRING.

\section{MATERIAL E MÉTODOS}

A área de estudo corresponde à bacia hidrográfica localizada na cabeceira do Rio Pardo, Município de Pardinho, na região Centro-Oeste do Estado de São Paulo; com uma área de 5334,36 ha, se situa entre as latitudes de $22^{\circ} 58^{\prime} 32^{\prime \prime} \mathrm{S}$ a $23^{\circ} 06^{\prime} 39^{\prime \prime} \mathrm{S}$ e longitudes de $48^{\circ} 20^{\prime} 28^{\prime \prime} \mathrm{W}$ Gr. a 48 26’ $08^{\prime \prime}$ W Gr.

O clima do município, segundo a classificação de Köppen é do tipo Cwa na depressão periférica ou baixada e Cwb no altiplano da cuesta onde está localizada a cidade de Pardinho; o tipo Cwa caracteriza-se por apresentar clima mesotérmico úmido com inverno seco, em que a temperatura média do mês mais quente é maior que $22^{\circ} \mathrm{C}$, apresentando os meses de julho e agosto como os mais secos; o tipo Cwb caracteriza-se por um tipo mesotérmico de inverno seco cujas temperaturas médias do mês mais quente não ultrapassam $22^{\circ} \mathrm{C}$ e do mês mais seco e mais frio é inferior a $18^{\circ} \mathrm{C}$.

Os solos ocorrentes são: Latossolo Vermelho Distrófico (LVd); Latossolo Vermelho Eutrófico (LVe); Neossolo Litólico Psamítico (RL); Alissolo Hipocrômico (AP) e Gleissolo Melânico Distrófico (GMd).

Utilizaram-se, como bases cartográficas, as cartas planialtimétricas de Botucatu (SF-22-R-IV-3) e Pardinho (SF-22X-II-1), 1:50000, com curvas de nível de 20 em 20 m, editadas pelo Instituto Brasileiro de Geografia e Estatística (IBGE, 1973); o mapa de solos, 1:10000 (Zimback, 1997) e a imagem no formato digital do ETM+ do Landsat-7, bandas 3, 4 e 5, órbita/ponto 220/76, passagem de 3/06/2001.

Para obtenção do mapa de vulnerabilidade à erosão, utilizou-se a metodologia proposta por Crepani et al. (2001), desenvolvida com base no conceito de ecodinâmica de Tricart (1977) e na utilização de imagens do Landsat-TM.

A análise e a interpretação das imagens foram feitas considerando-se os padrões fotográficos identificados pelas variações de cor, textura, forma, padrões de drenagem e relevo. A vulnerabilidade das unidades de paisagem foi estabelecida através de uma escala de valores (21 classes de 1.0 a 3.0) conforme Crepani et al. (2001), de acordo com a relação morfogênese/pedogênese, analisando-se cada um dos temas: geologia, geomorfologia, pedologia, vegetação e clima; posteriormente, fez-se uma classificação do grau de estabilidade ou vulnerabilidade de cada unidade ambiental, segundo as relações entre os processos de morfogênese e pedogênese, sendo possível elaborar a carta de vulnerabilidade natural à erosão, em escala 1:250000. Os planos de informações (PIs) contidos dentro do projeto foram utilizados para armazenar informações da área de estudo, oriundas de diferentes fontes.

Foram inseridos, no banco de dados, os PIs: rede de drenagem, curvas de nível, limites da bacia hidrográfica, imagens do sensor ETM+ do Landsat-7, mapas de solos, geológico e geomorfológico e dados de precipitação.

O processamento digital consistiu de uma série de etapas computacionais para extrair as informações desejadas, como: digitalização das curvas de nível para a elaboração do mapa de declividade; importação do mapa de solos; digitalização de polígonos do mapa geológico; extração das informações 
de uso do solo com base na imagem do sensor ETM+ Etra- $^{+}$ vés de segmentação, classificação e posterior edição matricial para correção dos erros ocasionados pelo algoritmo classificador, auxiliado pelo trabalho de campo; ponderação por grade numérica dos mapas temáticos para valores adotados por Crepani et al. (2001); edição do mapa cadastral dos polígonos de análise de padrões; processamento da média zonal em cada polígono de análise de padrões, de acordo com os valores de cada mapa ponderado; fatiamento da grade numérica obtida da média zonal para a elaboração do mapa de vulnerabilidade a erosão e criação da tabela cadastral para consulta espacial.

A segmentação de imagem é um procedimento adotado antes da fase de classificação, na tentativa de solucionar o problema da subjetividade do treinamento na classificação supervisionada, a qual se baseia nos procedimentos de análise dos píxels; através deste procedimento a imagem é dividida em regiões espectralmente homogêneas, em que algumas dessas áreas são utilizadas como treinamento do classificador.

O procedimento de segmentação exige que o analista forneça dois tipos de limiares: o limiar de similaridade e o de área. Após vários testes, definiu-se o valor 8 para o limiar de similaridade e 10 para o limiar de área, em razão de serem esses valores os que melhor representaram as regiões de interesse para o mapeamento de uso do solo na área de estudo; em seguida, realizou-se a classificação não-supervisionada através do classificador ISOSEG, com limiar de aceitação de 75\%; as classes de uso do solo que foram associadas às classes temáticas, foram: água, mata nativa, reflorestamento, cultura anual, cultura perene, pastagem, várzea e cidade (Tabela 1).

Tabela 1. Valores de vulnerabilidade a erosão associados às classes de uso do solo

\begin{tabular}{lc}
\hline Classe de Uso do Solo & Valor de Vulnerabilidade \\
Água & 1,5 \\
Cultura Perene & 2,5 \\
Cultura Anual & 3,0 \\
Pastagem & 2,0 \\
Mata & 1,0 \\
Várzea & 3,0 \\
Cidade & 1,0 \\
Reflorestamento & 1,5 \\
\hline
\end{tabular}

Elaborou-se o mapa de uso do solo com base no procedimento utilizado para o mapa de vulnerabilidade, porém os valores de vulnerabilidade (Tabela 1) diferem dos estipulados no projeto desenvolvido, por Crepani et al. (2001). Esses valores eram dirigidos para a vegetação típica da Floresta Amazônica; como a vegetação difere da Amazônia, surgiu a necessidade de se associar outros valores de vulnerabilidade, de acordo com a vegetação típica da região, considerando-se como e quanto esta vegetação afeta a estrutura física do solo.

A digitalização das isolinhas foi realizada na tela do monitor, através da função edição vetorial, contida no aplicativo SPRING; para tal, as cartas foram escaneadas e transforma- das do formato TIFF para o formato GRIB, no módulo IMPIMA do SPRING e, então, importadas para o banco de dados; posteriormente, realizou-se o registro utilizando-se, como referência, as cartas planialtimétricas originais; uma vez que, feito o registro, os dados foram importados para o projeto Pardinho como categoria Imagem, isto é, no formato "raster", semelhante à imagem do ETM+ do Landsat-7. Através da edição vetorial, criou-se um Modelo Numérico de Terreno com as informações das isolinhas, as quais foram transformadas em uma grade triangular, a fim de gerar a declividade; após gerada a declividade, a etapa seguinte foi fazer o fatiamento dos dados; desta forma, um plano de informação da categoria numérica originará um Plano de Informação de categoria temática representando um aspecto particular do modelo numérico de terreno; conseqüentemente, cada fatia deve ser associada a uma classe temática previamente definida no esquema conceitual do banco de dados ativo.

A definição dos intervalos de cotas ou fatias e os valores para a vulnerabilidade a erosão (Tabela 2) foram realizados conforme Crepani et al. (2001). Os intervalos de cotas são definidos no SPRING, através dos modos fixo e variável.

Tabela 2. Valores de vulnerabilidade para a declividade das encostas

\begin{tabular}{|c|c|c|}
\hline \multicolumn{2}{|c|}{ Declividade } & \multirow{2}{*}{ Vulner./Estabilid. } \\
\hline ilgrau & $\%$ & \\
\hline$<2$ & $<3,5$ & 1,0 \\
\hline $2-3,3$ & $3,5-5,8$ & 1,1 \\
\hline $3,3-4,6$ & $5,8-8,2$ & 1,2 \\
\hline $4,6-5,9$ & $8,2-0,3$ & 1,3 \\
\hline $5,9-7,3$ & $10,3-2,9$ & 1,4 \\
\hline $7,3-8,6$ & $12,9-15,1$ & 1,5 \\
\hline $8,6-9,9$ & $15,1-17,4$ & 1,6 \\
\hline $9,9-11,2$ & $17,4-19,8$ & 1,7 \\
\hline $11,2-12,5$ & $19,8-22,2$ & 1,8 \\
\hline $12,5-13,8$ & $22,2-24,5$ & 1,9 \\
\hline $13,8-15,2$ & $24,5-27,2$ & 2,0 \\
\hline $15,2-16,5$ & $27,2-29,6$ & 2,1 \\
\hline $16,5-17,8$ & $29,6-32,1$ & 2,2 \\
\hline $17,8-19,1$ & $32,1-34,6$ & 2,3 \\
\hline $19,1-20,4$ & $34,6-37,2$ & 2,4 \\
\hline $20,4-21,7$ & $37,2-39,8$ & 2,5 \\
\hline $21,7-23,0$ & $39,8-42,4$ & 2,6 \\
\hline $23,0-24,4$ & $42,4-45,3$ & 2,7 \\
\hline $24,4-25,7$ & $45,3-48,1$ & 2,8 \\
\hline $25,7-27$ & $48,1-50$ & 2,9 \\
\hline$>27$ & $>50$ & 3,0 \\
\hline
\end{tabular}

Gerou-se o mapa temático da geologia da área (Tabela 3) a partir de dados digitalizados de mapas geológicos em formato analógico e o mapa de solos (Tabela 4) foi importado no formato raster e posteriormente editado matricialmente, a fim de se corrigir as unidades de solo de acordo com o novo Sistema Brasileiro de Classificação de Solos (Oliveira et al., 1999).

Como existe apenas um único valor médio de precipitação para toda a região de estudo, o mapa de amplitude de precipitação foi obtido através de uma edição matricial em cima do limite da bacia (Tabela 5). 
Tabela 3. Escala de vulnerabilidade à denudação das rochas mais comuns

\begin{tabular}{lc}
\hline \multicolumn{1}{c}{ Rocha } & Vulner./Estabilid. \\
Quartzitos ou metaquartzitos & 1,0 \\
Riólito, Granito, Dacito & 1,1 \\
Granodiorito, Quartzo Diorito, Granulitos & 1,2 \\
Migmatitos, Gnaisses & 1,3 \\
Fonólito, Nefelina Sienito, Traquito, Sienito & 1,4 \\
Andesito, Diorito, Basalto & 1,5 \\
Anortosito, Gabro, Peridotito & 1,6 \\
Milonitos, Quartzo, Clorita xisto & 1,7 \\
Anfibolito Kimberlito, Dunito & 1,8 \\
Actinolita xisto & 1,9 \\
Estaurolita xisto, Xistos granatiferos & 2,0 \\
Filito, Metassiltito & 2,1 \\
Ardósia, Metargilito & 2,2 \\
Mármores & 2,3 \\
Arenitos quartzosos ou ortoquartzitos & 2,4 \\
Conglomerados, Subgrauvacas & 2,5 \\
Grauvacas, Arcózios & 2,6 \\
Siltitos, Argilitos & 2,7 \\
Folhelhos & 2,8 \\
Calcários, Dolomitos, Margas, Evaporitos & 2,9 \\
Sedimentos Inconsolidados: Aluviões, Colúvios etc. & 3,0 \\
\hline
\end{tabular}

Fonte: Adaptada de Crepani et al. (2001)

Tabela 4. Valores de vulnerabilidade/estabilidade dos solos (Crepani et al., 2001)

\begin{tabular}{lcc}
\hline Classes de solo & Legenda & Vulnerabil./Estabilidade \\
Latossolo Amarelo & LA & 1,0 \\
Latossolo Vermelho- & LVA & 1,0 \\
Amarelo & LV & 1,0 \\
Latossolo Vermelho & LB & 1,0 \\
Latossolo Bruno & & 1,0 \\
Argissolo & $\mathrm{P}$ & 2,0 \\
Luvissolo & $\mathrm{T}$ & 2,0 \\
Alissolo & $\mathrm{A}$ & 2,0 \\
Nitossolo & $\mathrm{N}$ & 2,0 \\
Chernossolo & $\mathrm{M}$ & 2,0 \\
Planossolo & $\mathrm{S}$ & 2,0 \\
Espodossolo & $\mathrm{E}$ & 2,0 \\
Cambissolos & $\mathrm{C}$ & 2,5 \\
Neossolo & $\mathrm{R}$ & 3,0 \\
Neossolo Quartzarênico & $\mathrm{RQ}$ & 3,0 \\
Vertissolo & $\mathrm{V}$ & 3,0 \\
Organossolo & 0 & 3,0 \\
Gleissolo & $\mathrm{G}$ & 3,0 \\
Plintossolo & $\mathrm{F}$ & 3,0 \\
Chernossolo Rêndzico & $\mathrm{MD}$ & 3,0 \\
Afloramento Rochoso & $\mathrm{AR}$ & 3,0 \\
\hline
\end{tabular}

A ponderação consiste em transformar os mapas temáticos em uma grade numérica, em que cada classe recebe um peso. Fez-se o processamento através do LEGAL no SPRING, constituído de sentenças (linhas de comando), que estão estruturadas em três partes: declarações, instanciações e operações (álgebra de mapas); na instanciação, recuperam-se os dados já existentes do banco de dados ou se cria um novo PI, que poderá, então, ser associado ao resultado de operações em LEGAL.
Tabela 5. Escala de erosividade da chuva e valores de vulnerabilidade à erosão

\begin{tabular}{|cc|}
\hline $\begin{array}{c}\text { Intensidade Pluviométrica } \\
\text { mm mês }\end{array}$ & Vulnerabilidade \\
\hline$<50$ & 1,0 \\
$50-75$ & 1,1 \\
$75-100$ & 1,2 \\
$100-125$ & 1,3 \\
$125-150$ & 1,4 \\
$150-175$ & 1,5 \\
$175-200$ & 1,6 \\
$200-225$ & 1,7 \\
$225-250$ & 1,8 \\
$250-275$ & 1,9 \\
\hline $275-300$ & 2,0 \\
$300-325$ & 2,1 \\
\hline $325-350$ & 2,2 \\
$350-375$ & 2,3 \\
\hline $375-400$ & 2,4 \\
$400-425$ & 2,5 \\
$425-450$ & 2,6 \\
$450-475$ & 2,7 \\
$475-500$ & 2,8 \\
$500-525$ & 2,9 \\
\hline$>525$ & 3,0 \\
\hline
\end{tabular}

Fonte: Crepani et al. (2001)

Na elaboração do mapa de vulnerabilidade à erosão, foi necessário determinar regiões espectralmente homogêneas (Tabela 6), utilizando-se da segmentação por crescimento de regiões. A segmentação foi então mosaicada para um Plano de Informação Cadastral e, por edição vetorial, ajustada em 1.320 polígonos, os quais são rotulados na categoria objetos, para servirem de base para uma tabela de atributos realizando-se, para cada polígono, o cálculo médio dos pesos de cada tema, ou seja, de cada grade ponderada dos temas declividade, geologia, solo, uso do solo e pluviosidade, associando-se um valor e, gerando nova grade. Este processo foi realizado no LEGAL, através da edição de um programa denominado Média Zonal.

A grade resultante da média zonal foi então fatiada de intensidade pluviométrica, descrita em Crepani et al. (2001), gerando o mapa de vulnerabilidade a erosão.

Realizou-se o cadastro dos dados a partir dos seguintes procedimentos: exportação dos polígonos e seus respectivos identificadores (rotulação espacial do polígono) no formato ASCII; importação apenas dos identificadores no formato ASCII para o Plano de Informação dos polígonos; procedimento este realizado para não haver a necessidade de rotular todos os polígonos, individualmente; desta forma, elaborou-se uma tabela como categoria objeto, denominada cadastral, com os seguintes atributos: identificador, código, rótulo, área e perímetro do polígono.

Depois de elaborado o mapa de vulnerabilidade, os dados de cada atributo foram inseridos na tabela a partir de uma programação computacional realizada pelo LEGAL e elaborada para um cadastro espacial inteligente do banco de dados, através do qual um usuário pode fazer uma consulta a respeito das propriedades de determinado polígono que, por outro lado, foram inseridas na tabela de atributos. 
Tabela 6. Escala de vulnerabilidade das unidades territoriais básicas

\begin{tabular}{|c|c|c|c|c|c|c|c|c|}
\hline \multirow{2}{*}{ Unidade de Paisagem } & \multicolumn{3}{|c|}{ Média } & \multirow{2}{*}{ Grau de Vulnerabilidade } & \multicolumn{4}{|c|}{ Grau de Saturação } \\
\hline & & & & & Verm & Verde & Azul & \\
\hline U1 & & 3,0 & & & 255 & 0 & 0 & \\
\hline U2 & & 2,9 & & & 255 & 51 & 0 & \\
\hline U3 & & 2,8 & & Vulnerável & 255 & 102 & 0 & \\
\hline U4 & V & 2,7 & & & 255 & 153 & 0 & \\
\hline U5 & U & 2,6 & & & 255 & 204 & 0 & \\
\hline U6 & $\mathbf{L}$ & 2,5 & E & Moderadamente & 255 & 255 & 0 & \\
\hline U7 & N & 2,4 & $s$ & Vulnerável & 204 & 255 & 0 & \\
\hline U8 & $E$ & 2,3 & $\begin{array}{lll}T & \\
\end{array}$ & & 153 & 255 & 0 & \\
\hline U9 & $\mathbf{R}$ & 2,2 & A & & 102 & 255 & 0 & \\
\hline U10 & A & 2,1 & B & Medianamente & 51 & 255 & 0 & \\
\hline U11 & B & 2,0 & I & Estável & 0 & 255 & 0 & \\
\hline U12 & I & 1,9 & $\mathbf{L}$ & Vulnerável & 0 & 255 & 51 & \\
\hline U13 & L & 1,8 & I & & 0 & 255 & 102 & \\
\hline U14 & I & 1,7 & D & & 0 & 255 & 153 & \\
\hline U15 & D & 1,6 & A & Moderadamente & 0 & 255 & 204 & \\
\hline U16 & A & 1,5 & D & Estável & 0 & 255 & 255 & \\
\hline U17 & D & 1,4 & $\mathrm{E}$ & & 0 & 204 & 255 & \\
\hline U18 & E & 1,3 & & & 0 & 153 & 255 & \\
\hline U19 & & 1,2 & & & 0 & 102 & 255 & \\
\hline U20 & & 1,1 & & Estável & 0 & 51 & 255 & \\
\hline U21 & & 1,0 & & & 0 & 0 & 255 & \\
\hline
\end{tabular}

Fonte: Crepani et al. (2001)

\section{RESULTADOS E DISCUSSÕES}

A classificação digital das imagens do Landsat-7 (Figura 1 e Tabela 7) permitiu através dos valores ponderados para a vul- nerabilidade a erosão devido ao uso do solo mapear, discriminar e avaliar 8 classes de uso da terra: água, cultura perene e anual, pastagem, mata, várzea, cidade e reflorestamento.

As classes de uso de maior ocorrência na área de estudo,
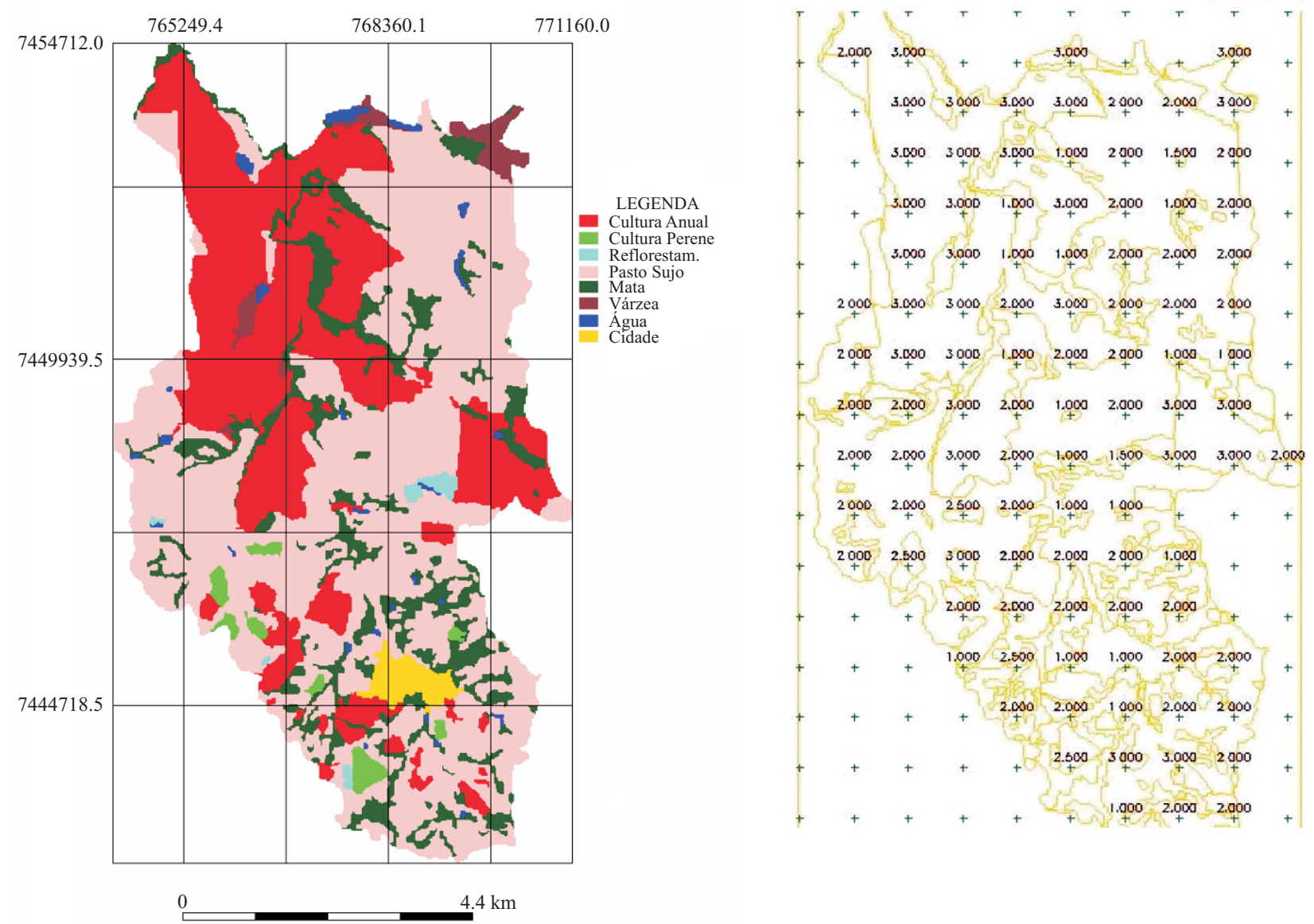

Figura 1. Classes de uso do solo e grade de ponderação da Região do Alto Rio Pardo, Pardinho, SP 
Tabela 7. Classes de uso do solo e respectivos valores de vulnerabilidade da Região do Alto Rio Pardo, Pardinho, SP

\begin{tabular}{lccc}
\hline $\begin{array}{l}\text { Classe de Uso } \\
\text { do Solo }\end{array}$ & $\begin{array}{c}\text { Área } \\
\text { (ha) }\end{array}$ & $\begin{array}{c}\text { Área } \\
\mathbf{( \% )}\end{array}$ & $\begin{array}{c}\text { Valor de } \\
\text { Vulnerabilidade }\end{array}$ \\
\hline Água & 60,62 & 1,12 & 1,5 \\
Cultura Perene & 78,75 & 1,46 & 2,5 \\
Cultura Anual & $1.606,37$ & 29,88 & 3,0 \\
Pastagem & $2.684,93$ & 49,94 & 2,0 \\
Mata & 745,31 & 13,86 & 1,0 \\
Várzea & 96,12 & 1,79 & 3,0 \\
Cidade & 77,94 & 1,45 & 1,0 \\
Reflorestamento & 26,75 & 0,50 & 1,5 \\
Total & $5.376,79$ & 100,00 & \\
\hline
\end{tabular}

foram as pastagens, com valores de vulnerabilidade, a pastagem, que representa uma classe de uso sem muita remoção e revolvimento do solo, foi considerada mediana quanto a influência à erosão do solo, recebendo um peso de valor 2, sendo que as culturas anuais predominaram em quase $30 \%$, com área de 1606,37 ha; por ser a classe que mais afeta a estrutura física do solo, recebeu peso de valor 3 mostrando, com isso, a vocação regional para agropecuária, conforme Campos (1997).

O índice mostra que as pastagens são cultivadas mais extensivamente, ou seja, apresentam ocorrência de plantas invasoras, mostrando vulnerabilidade média (2) e são mais vulnerável que as matas (1) porém, menos vulneráveis que as culturas anuais (3), várzeas (3) e cultura perene $(2,5)$.

A área de estudo pode ser classificada como extremamente vulnerável, pois as classes de uso da terra mais vulneráveis predominam em quase $80 \%$ da área total, ou seja, é $29,88 \%$ constituída de culturas anuais (vulnerabilidade 3) e 49,94\% de pastagens (vulnerabilidade 2).

Em razão de protegerem mais o solo em termos de vulnerabilidade, as matas mostraram que precisam ser mais bem preservadas para atender o mínimo de reserva florestal (20\%) exigido pelo Código Florestal Brasileiro, tendo em vista que apresentam baixa vulnerabilidade (índice 1,0).

A carta clinográfica (Figura 2 e Tabela 8) mostra que a

Tabela 8. Valores de representatividade na área das classes de declividade da Região do Alto Rio Pardo, Pardinho, SP

\begin{tabular}{ccc}
\hline $\begin{array}{c}\text { Classes de declive } \\
(\%)\end{array}$ & $\begin{array}{c}\text { Representatividade } \\
\text { na área (\%) }\end{array}$ & Vulnerabilidade \\
$0-2$ & 38,81 & 1,0 \\
$2-5$ & 4,46 & 1,1 \\
$5-10$ & 22,94 & 1,25 \\
$10-20$ & 27,91 & 1,6 \\
$20-30$ & 4,78 & 2,0 \\
$30-50$ & 1,03 & 2,6 \\
$>50 \%$ & 0,05 & 3,0 \\
\hline
\end{tabular}
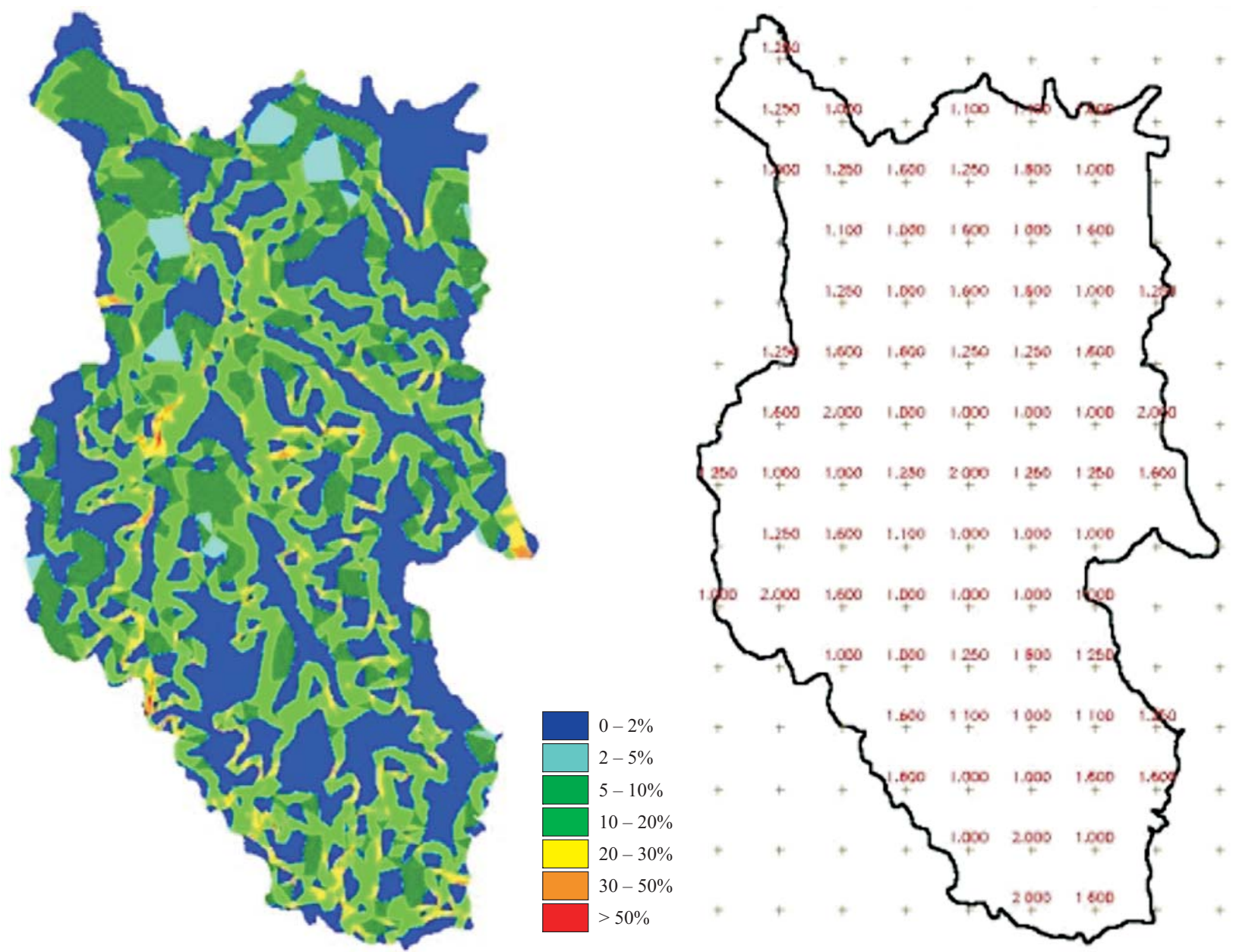

Figura 2. Carta clinográfica e a grade de ponderação da Região do Alto Rio Pardo, Pardinho, SP 
maior parte da área de estudo (94,14\%) possui declividade variando de 0 a $20 \%$ e vulnerabilidade oscilando de 1 a 1,6; desta forma, diz-se que a área é representada por relevo plano a suave ondulado e a declividade é pouca representativa na área em relação à erosão do solo, pois mais de $66 \%$ dessas declividades foram considerados estáveis (66,22\%), enquanto as outras declividades, com mais de $27 \%$, medianamente estáveis podendo-se dizer que mais de 3/5 da área são estáveis quanto à declividade e apenas $0,05 \%$ apresenta alta vulnerabilidade ( $>50 \%$ declividade).

O mapa geológico que gerou os valores de vulnerabilidade à erosão de cada classe geológica (Figura 3) permitiu verificar que a classe $\mathrm{Km}$, em que a rocha predominante é o arenito quartsoso e o valor de vulnerabilidade à erosão do solo, 2,4 é a que mais afeta o solo da área, em termos de erosão, porém se enquadra como resistência medianamente vulnerável, enquanto a classe JKsg, foi geologicamente reconhecida como medianamente estável, haja vista que o índice de vulnerabilidade de 1,5 praticamente não afeta o solo, em termos de estabilidade.

Os solos (Figura 4) permitiram classificar o grau de vul- nerabilidade à erosão como vulnerável e medianamente vulnerável, pois o índice de vulnerabilidade variou de 1 para 2, exceto para os solos ao longo do rio principal da bacia que receberam o valor 3,0. A pluviosidade influenciou pouco a vulnerabilidade do solo à erosão, pois representa um valor de 1,3 .

O mapa de vulnerabilidade à erosão do solo (Figura 5 e Tabela 9) permitiu constatar que o grau de estabilidade de cada unidade ambiental variou de 1,1 a 2,2, ou seja, sendo classificado, respectivamente, de baixa a medianamente estável/vulnerável.

O grau de vulnerabilidade mostrou, também, que mais de 75\% da área são moderadamente estáveis (vulnerabilidade de 1,4 a 1,7); já a Figura 5 e a Tabela 9, permitem verificar que a área possui valores de vulnerabilidade do solo a erosão entre 1,1 e 2,2, isto é, de baixa a média vulnerabilidade e que a vulnerabilidade máxima foi de 2,2, representada pela cor verde claro.

Pode-se dizer que a quase totalidade (96,45\%) da área pertence às classes de vulnerabilidade moderadamente estável (75,27\%) e medianamente estável/vulnerável (21,18\%), pois
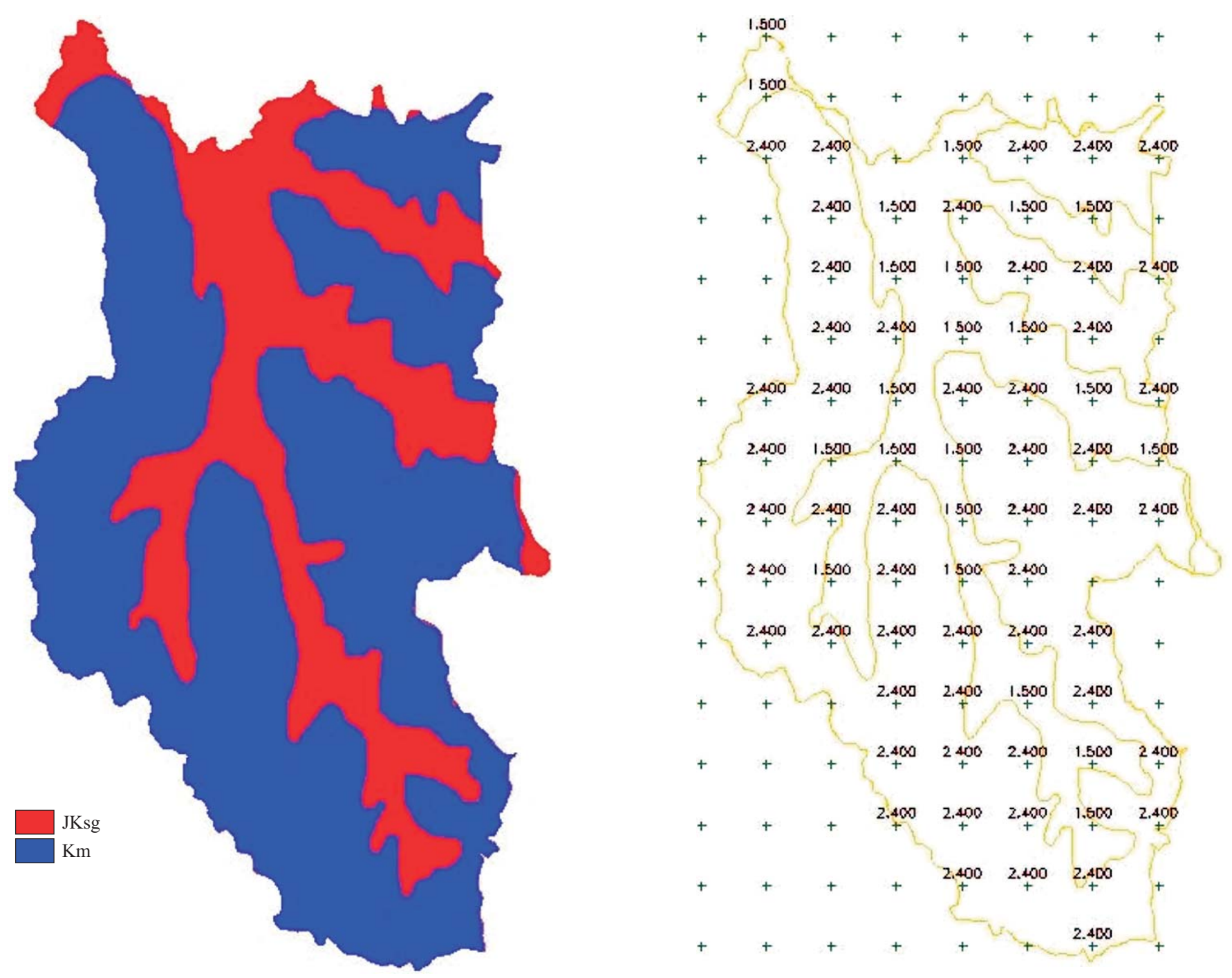

Figura 3. Mapa geológico e grade de ponderação da Região do Alto Rio Pardo, Pardinho, SP 

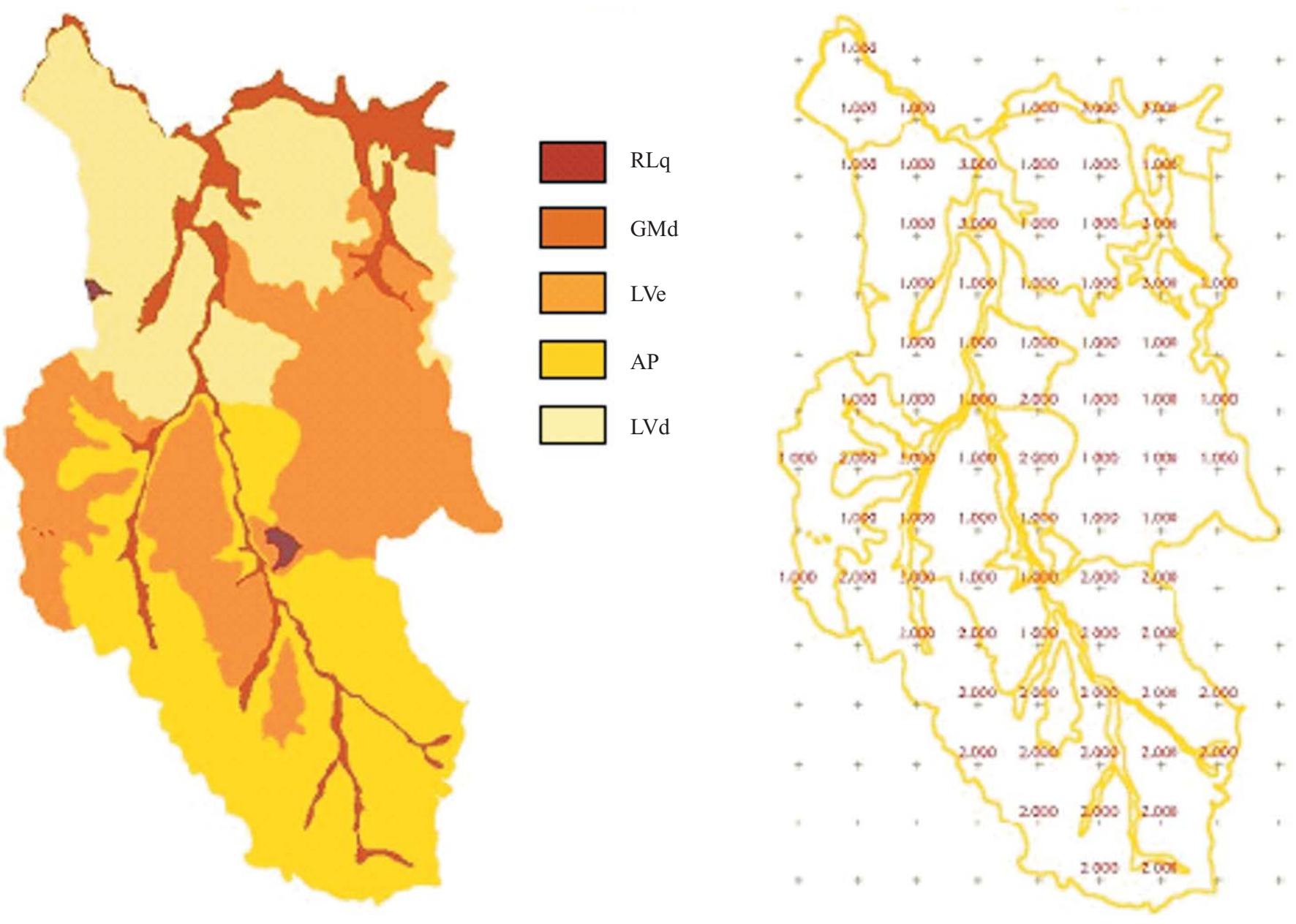

Figura 4. Mapa de solos e grade de ponderação da Região do Alto Rio Pardo, Pardinho, SP

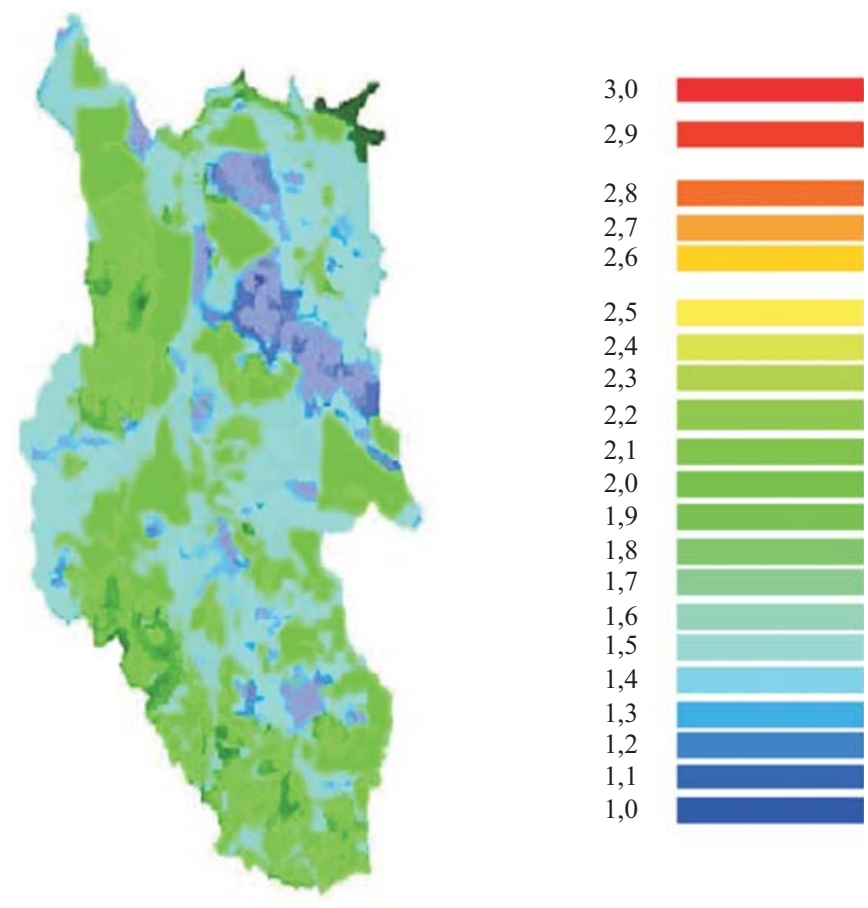

Figura 5. Mapa de vulnerabilidade à erosão do solo e a grade de ponderação da Região do Alto Rio Pardo, Pardinho, SP
Tabela 9. Classes de vulnerabilidade do solo a erosão na área

\begin{tabular}{|c|c|c|c|c|c|c|}
\hline $\begin{array}{l}\text { Unidade de } \\
\text { Paisagem }\end{array}$ & & Média & & $\begin{array}{c}\text { Grau de } \\
\text { Vulnerabilidade }\end{array}$ & $\begin{array}{l}\text { Área } \\
\text { (ha) }\end{array}$ & $\begin{array}{c}\text { Área } \\
\text { (\%) }\end{array}$ \\
\hline U1 & & 3,0 & & & 0 & 0 \\
\hline U2 & & 2,9 & & & 0 & 0 \\
\hline U3 & & 2,8 & & Vulnerável & 0 & 0 \\
\hline U4 & V & 2,7 & & & 0 & 0 \\
\hline U5 & U & 2,6 & & & 0 & 0 \\
\hline U6 & $\mathbf{L}$ & 2,5 & $\mathbf{E}$ & Moderadamente & 0 & 0 \\
\hline U7 & N & 2,4 & $s$ & Vulnerável & 0 & 0 \\
\hline U8 & $E$ & 2,3 & $T$ & & 0 & 0 \\
\hline U9 & $\mathbf{R}$ & 2,2 & A & & 0,4 & 0,006 \\
\hline U10 & A & 2,1 & B & Medianamente & 46,9 & 0,88 \\
\hline U11 & B & 2,0 & I & Estável/ & 62,4 & 1,17 \\
\hline U12 & I & 1,9 & $\mathbf{L}$ & Vulnerável & 174,9 & 3,29 \\
\hline U13 & L & 1,8 & I & & 840,1 & 15,83 \\
\hline U14 & I & 1,7 & D & & 1367,5 & 25,77 \\
\hline U15 & D & 1,6 & A & Moderadamente & 1213,1 & 22,86 \\
\hline U16 & A & 1,5 & D & Estável & 915,8 & 17,26 \\
\hline U17 & D & 1,4 & $\mathrm{E}$ & & 497,8 & 9,38 \\
\hline U18 & E & 1,3 & & & 120,8 & 2,28 \\
\hline U19 & & 1,2 & & & 62,5 & 1,17 \\
\hline U20 & & 1,1 & & Estável & 3,06 & 0,06 \\
\hline U21 & & 1,0 & & & 0 & 0 \\
\hline
\end{tabular}

R. Bras. Eng. Agríc. Ambiental, v.11, n.6, p.628-636, 2007. 
somente 3,55\% pertencem às classes estáveis, cuja ocorrência é devida, provavelmente, ao fato dessa área se compor de solos nos quais o índice variou de 1 a 2 e por apresentar cobertura vegetal que cobre o solo medianamente (pastagens) e relevo plano a suave ondulado (0 a $20 \%$ de declive).

\section{CONCLUSÕES}

1. Os dados coletados pelo sensor "Thematic Mapper" do Landsat, geraram informações valiosas sobre os diferentes alvos de ocupação do solo, sendo muito úteis para o mapeamento utilizado no banco de dados.

2. O sistema de informações geográficas SPRING foi eficiente na determinação da ocupação do solo e na determinação das classes de vulnerabilidade a erosão.

3. 95\% da área total apresentam grau de vulnerabilidade classificado como medianamente e moderadamente estável, devido à presença de solos de média jovialidade, em relevo suave ondulado (declividade de 5 a 20\%) e coberto na maior parte, por pastagem e cultura anual nas unidades de paisagem; além disso, a região apresenta mais de 3/4 da sua área com grau de vulnerabilidade moderadamente estável.
4. Quase $80 \%$ da área são ocupados por cultura (29,88\%) e pastagem $(49,27 \%)$ mostrando a vocação regional para a agropecuária.

\section{LITERATURA CITADA}

Campos, S. Diagnóstico físico conservacionista da Bacia do Rio Lavapés - Botucatu, SP. Botucatu: FCA/UNESP, 1997. 140p. Tese Livre-Docência

Crepani, E.; Medeiros, J. S. de; Azevedo, L. G. DE.; Hernandez Filho, P.; Florenzano, T. G.; Duarte, V. Curso de sensoriamento remoto aplicado ao zoneamento ecológico-econômico. São José dos Campos: INPE, 2001. 25p.

IBGE - Instituto Brasileiro de Geografia e Estatística. Secretaria de Planejamento da Presidência da República - Carta do Brasil Quadrícula de Botucatu e Pardinho. Escala 1:50000, 1973.

Oliveira, J. B. de; Camargo, M. N.; Rossi, M.; Calderan Filho. Mapa pedológico do Estado de São Paulo: Legenda expandida. Campinas: EMBRAPA. 1999. 64p.

Tricart, J. Ecodinâmica. Rio de Janeiro: IBGE-SUPREN, 1977. 91p.

Zimback, C. R. L. Mapa de solos da bacia do Rio Pardo, SP. Botucatu: FEPAF; FCA/UNESP, 1997. 55p. 